University of Nebraska - Lincoln

DigitalCommons@University of Nebraska - Lincoln

Faculty Publications, Department of Child, Youth, and Family Studies

Child, Youth, and Family Studies, Department of

8-27-2006

\title{
Individual and Familial Stressors Among Rural Nebraskan, Bilingual, Paraprofessional Educators
}

\author{
Rochelle L. Dalla \\ University of Nebraska-Lincoln, rdalla1@unl.edu \\ William E. Lopez \\ University of Nebraska-Lincoln, wlopez2@unl.edu \\ Vicky O. Jones \\ University of Nebraska-Lincoln \\ Yan Ruth Xia \\ University of Nebraska-Lincoln, rxia2@unl.edu
}

Follow this and additional works at: https://digitalcommons.unl.edu/famconfacpub

Part of the Family, Life Course, and Society Commons

Dalla, Rochelle L.; Lopez, William E.; Jones, Vicky O.; and Xia, Yan Ruth, "Individual and Familial Stressors Among Rural Nebraskan, Bilingual, Paraprofessional Educators" (2006). Faculty Publications, Department of Child, Youth, and Family Studies. 50.

https://digitalcommons.unl.edu/famconfacpub/50

This Article is brought to you for free and open access by the Child, Youth, and Family Studies, Department of at DigitalCommons@University of Nebraska - Lincoln. It has been accepted for inclusion in Faculty Publications, Department of Child, Youth, and Family Studies by an authorized administrator of DigitalCommons@University of Nebraska - Lincoln. 


\title{
Individual and Familial Stressors Among Rural Nebraskan, Bilingual, Paraprofessional Educators
}

\author{
Rochelle L. Dalla \\ William E. Lopez \\ Vicky O. Jones \\ Yan Xia
}

University of Nebraska-Lincoln

\begin{abstract}
Individual (e.g., depression, learning styles) and familial (e.g., social support) factors affecting the psychosocial well-being of bilingual, rural Nebraska, paraprofessional educators were examined. Of 26 participants, 15 were first and 5 were second generation Hispanic immigrants. All were currently $(n=20)$ or formerly $(n=6)$ involved in an online, distance education, bachelor's degree program in elementary education, with English as a second language certification. Results from data analyses are presented, as are suggestions for working with unique populations.
\end{abstract}

\section{Resumen}

Se examinaron factores individuales (como depresión, y estilos de aprendizaje) y familiares (como apoyo social) que tienen impacto en el bienestar psico-social de educadores paraprofesionales bilingües rurales en Nebraska. De 26 participantes, 15 eran de primera y 5 eran de segunda generación inmigrantes Hispanos. Unos de ellos estaban involucrados en educación de bachillerato en educación primaria a distancia en línea, con certificación de Inglés como lenguaje secundario actualmente $(n=20)$, otros previamente $(n=6)$ lo habían estado. Resultados de los análisis de información son presentados, así como sugerencias para trabajar con poblaciones únicas.

Keywords: academic achievement, distance education, bilingual, immigration, Midwest, paraprofessional, psychosocial stressors

$\mathrm{T}$ he purpose of this exploratory investigation was to examine individual and familial factors that may significantly affect the psychosocial well-being of bilingual, rural Nebraskan, paraprofessional educators. Participants were involved (or formerly involved) in a 5-year "Career Ladder" project intended to increase the number of certified ESL (English as a second language) elementary school teachers in the state. However, for program goals to be achieved, participants must graduate. In all, 30 participants began 
the Career Ladder program in January 2003. Since that time, 9 have dropped out. Understanding and then addressing program participants' needs is paramount to their successful completion and, by extension, to the ability of rural Nebraska school systems to meet the needs of their ESL and LEP (limited English proficiency) students. Thus, the short-term goals of this investigation were to identify individual and familial factors that enhance and/or challenge participants' ability to successfully complete their online academic program. The long-term goals are to (a) apply the knowledge gained from this investigation to the creation of services designed to reduce or eliminate barriers of bilingual, rural women as they struggle to meet work or family demands; (b) improve the ability of institutions of higher education to understand barriers to academic success among placebound students; and (c) assist in the adaptation of online or distance education programs for client appeal and efficiency. This investigation represents one step toward meeting these long-term objectives.

\section{Background}

The rural Midwest, which encompasses hundreds of communities across 10 states, is undergoing dramatic social and economic change. Much of the change is attributed to rapid population growth as immigrant and migrant workers flock to rural communities in search of stable employment (Dalla, Cramer, \& Stanek, 2002). During the 1990s, Nebraska's foreign-born population increased 165\% - the seventh highest percentage increase in the country. Between 1990 and 2000, Nebraska gained 46,000 immigrants (Federation for American Immigration Reform, 2001). Of all immigrant groups, the Hispanic population growth rate in Nebraska has been the highest during the previous decade (WEBARCHIVES, 2000). ${ }^{1}$ About 156,000 people in Nebraska are immigrants or the children of immigrants; this equates to $9 \%$ of the state's population and is the sixth highest percentage in the country. Indeed, during the previous decade, the growth rate of Hispanics in Nebraska has eclipsed national averages. Nationally, Hispanics increased their numbers $38.8 \%$ (to 31.1 million), whereas in Nebraska the count swelled $108.3 \%$ (to 76,998; WEBARCHIVES, 2000). These numbers do not include illegal or undocumented immigrants.

Importantly, new immigration patterns have been established during the past two decades (Broadway, 1995; Fitchen, 1991) in which entire families are immigrating and taking up permanent residence, rather than solo men on temporary visits. Many rural, Midwestern communities have witnessed an economic resurgence because of the influx of immigrant laborers (Broadway, 2000; Dalla, Villarruel, Cramer, \& Gonzalez-Kruger, 2004) who are often willing to work at physically demanding, low-paying jobs (e.g., meatpacking) that local residents will not (Stull, Broadway, \& Erickson, 1992). Moreover, because of out-migration of local residents and particularly that of young adults (Allen, 1993), many rural communities are dependent on the influx of newcomers to maintain their population and economic base. Thus, the immigrant presence is not only a vitalizing factor in rural communities; in some instances it is a necessity for community survival. Still, rapid immigration into rural communities presents multiple challenges to community stability and harmony. The impact of rapid immigrant influx on rural (particularly meat-pack- 
ing) communities has been well established. Indeed, rural communities report economic and social benefits of immigrant influx (Bjerklie, 1995; Broadway, Stull, \& Podraza, 1994; Dalla et al., 2004). Negative impacts of rapid immigration on small communities, including limited and substandard housing, overburdened civic services, limited communication capabilities, and enhanced discrimination, are also well established (Gouveia \& Stull, 1995; Prochaska-Cue \& Ziebarth, 1997; Whitener, 2001). Rural school districts are particularly affected by rapid immigration, especially when immigrant newcomers have limited English-speaking skills.

\section{Educational Concerns}

In the past decade, the number of LEP students in Nebraska has increased by 1,000\%, with students representing 54 countries and speaking about 44 languages (Nebraska Department of Education, 2000). Meeting the needs of these students is particularly acute in rural areas. Unfortunately, rural districts have few or no bilingual (primarily Spanish) or ESL-endorsed teachers. Specifically, fewer than 200 Nebraska teachers, out of more than 22,000, hold an ESL endorsement (Nebraska Department of Education, 2000). The seven districts targeted by the Career Ladder Grant serve about 10,000 students with approximately 2,500 LEP students.

This is not only a state concern but a national concern. According to the English Language Acquisition, Language Enhancement, and Academic Achievement Act (2002), “The nation's ability to achieve the national education goals is increasingly dependent on its ability to educate LEP students who are linguistically and culturally diverse" (n.p.). Importantly, several purposes of the English Language Acquisition, Language Enhancement, and Academic Achievement Act include the following:

(1) help ensure that children with limited English proficiency . . attain English proficiency, develop high levels of academic attainment in English, and meet the same challenging State academic content and student academic achievement standards as all children are expected to meet; (2) assist State educational agencies and local education agencies to develop and enhance their capacity to provide high-quality instructional programs designed to prepare limited English proficient children, including immigrant children and youth, to enter all-English instruction settings; ... (5) assist State educational agencies, local educational agencies, and schools to build their capacity to establish, implement, and sustain language instruction education programs and programs of English language development for limited English proficient children; ... and (9) provide State educational agencies and local educational agencies with the flexibility to implement language instruction educational programs, based on scientific research on teaching LEP children.

The Career Ladder Program was established to assist rural Nebraska school districts in meeting the needs of their LEP students through teacher education and preparation. 


\section{Career Ladder Grant}

The Career Ladder Grant will significantly increase the capacity of several rural Nebraska school districts to effectively address the needs of the LEP and ESL students by adding a substantial number of bilingual and ESL-endorsed elementary teachers to their ranks. Still, participants must complete the program for program goals to be achieved. Given that nine have dropped out since the program's inception, this investigation was intended to identify factors that challenge and/or promote successful program completion.

\section{Method}

\section{Participants}

A total of 26 individuals composed the final sample; 25 of the 26 were female. When interviewed, they ranged in age from 22 to 48 (average age $=34.8$ ). The majority $(n=$ 21) were married. Three participants were single, and two reported coresidence with intimate partners. Most $(n=24)$ had children. The mean number of children of each was 2.5 (range $=1-4)$. Most participants were first $(n=15)$ or second $(n=5)$ generation Hispanic immigrants. First generation immigrants reported living in the United States, on average, 30.5 years (range $=4-37$ years). The majority of first and second generation immigrants reported Mexico $(n=17)$ as their country of origin. Other home countries included Guatemala $(n=1)$, Peru $(n=1)$, and Honduras $(n=1)$.

When interviewed, participants lived in various rural Nebraska communities, with most reporting South Sioux City $(n=10)$, Madison $(n=4)$, Schuyler $(n=3)$, or Norfolk $(n$ $=3$ ) as their place of residence. They had lived in their respective communities an average of 10 years (range $=2-36$ years). Most $(n=17)$ owned their own homes, and the majority $(n=15)$ also reported an annual total income of less than $\$ 29,999.00$. The average number of people living in each residence was 4.2 (range $=2-6$ ).

With regard to education, four participants had received their general equivalency degrees, and two were in the process of earning this degree. Among those who had not completed high school, they reported an average of 8.4 years of public education (range $=7-11$ years). As a whole, the group reported an average of 2 years of college experience (range $=6$ months -4 years). Six of the 26 participants had dropped out of the Career Ladder educational program.

\section{Procedures}

Participants were located through their involvement in the Career Ladder program. The Career Ladder coordinator attempted to contact all $(N=30)$ active and former Career Ladder participants via telephone and e-mail. She was able to reach 26 . The purpose of the research investigation was explained to each, and they were informed that, should they choose to participate in the research, their Career Ladder involvement would not be affected. All 26 expressed interest in participating in the research. A letter outlining the 
methodological details of the investigation, and potential risks and benefits of participating, was then sent to each. After receiving the letter, participants were again contacted by the Career Ladder coordinator, who arranged an interview between each participant and the principal investigator in a place that was private and conveniently located (e.g., place of work or residence).

Participants first completed a series of self-report questionnaires. (All were given the choice of completing the survey instruments on their own or of having questions and response choices read to them.) They were then engaged in an in-depth, open-ended, audiotaped interview. Interviews focused on marital strain or support, household and parenting division of labor, parenting concerns, familial strengths, and Career Ladder program strengths and challenges. (This investigation focuses on the survey data and the interview data related to program strengths and challenges only.) All audiotaped interviews were then transcribed by trained graduate-level research assistants. The entire process lasted an average of 75 minutes (range $=60-120$ minutes). Participants were compensated for their time.

\section{Instrumentation}

In addition to completing a demographic form, participants completed five additional survey instruments. A description of each follows.

The Acculturation Stress Scale. The Acculturation Stress Scale (Mena, Padilla, \& Maldonado, 1987) was used to assess acculturation and perceived discrimination. It consists of 24 items measuring acculturative stress in social, attitudinal, familial, and environmental contexts and perceived discrimination. Sample items include, for instance, "I have more barriers to overcome than most people," and "In looking for a good job, I sometimes feel that my ethnicity is a limitation." Participants indicated whether each statement applied to themselves by circling either yes or no. A score of 1 was given for each applicable (i.e., yes) statement; a score of 0 was given if the statement did not apply. A total applicability score was created by summing all items. Next, for each statement that applied, participants indicated how stressful it was, with response choices ranging from 1 (not stressful) to 5 (extremely stressful). An average total acculturation stress score was then computed by summing scores on each individual item. Only first and second generation immigrants $(n$ $=20$ ) completed this instrument.

The Personal Resource Questionnaire - Part 2 (PRQ85). The PRQ85 (Weinert, 1987) instrument is a 25-item scale that assesses perceptions of social support. Sample items include, for instance, "I belong to a group in which I feel important," and "I spend time with others who have the same interests I do." Participants indicated the extent to which they agreed or disagreed with each statement by using a response scale ranging from 1 (strongly disagree) to 7 (strongly agree).

The instrument also consists of three subscales. The intimacy/assistance subscale was designed to measure feelings of being loved and cared about by others and perceptions that help and guidance is available from network members. The subscale consists of 12 
items, including, for instance, "There is someone I feel close to who makes me feel secure," and "I have relatives or friends that will help me out even if I can't pay them back." The integration/affirmation subscale consists of eight items and measures perceptions of being integrated into a group with similar interests and values. An example of an item from the social integration subscale includes, "I have people to share social events and fun activities with." Finally, the nurturance subscale, composed of five items, was designed to assess support a person provides to others, especially younger people. For instance, "I have the opportunity to encourage others to develop their interests and skills," is a nurturance item.

In scoring the PRQ85, a total support score is obtained by summing all items (with total scores ranging from a possible low of 25 to a high of 175). Subscale scores are obtained by summing all items comprising each. Five items were reverse coded so that higher scores indicated perceptions of more effective social support networks. The PRQ85 demonstrates adequate internal consistency, test-retest reliability, and construct validity among general and Mexican American samples (Hovey, 2000).

The Depression/Center for Epidemiological Studies-Depress (CES-D). The CES-D (Radloff, 1977) was administered to assess depressed mood, feelings, and perceptions. This instrument consists of 20 statements (e.g., "I had trouble keeping my mind on what I was doing," and "I felt depressed") to which participants indicate the extent to which each applied to them during the previous week. Response choices range from 0 (rarely or less than 1 day) to 3 (most or all of the time or 5-7 days). Four items were reverse coded so that higher scores indicated the presence of more depressive symptoms. Scores were summed to reveal a total depressive symptom score (ranging from a possible low of 0 to a high of 60). A score at or above 16 indicates symptoms of clinical depression (Radloff, 1977). This instrument has been successfully used with general and Mexican American populations (Roberts, 1980).

Language use. Participants completed a 12-item instrument designed to determine their use of both Spanish and English. Participants complete each item on a 5-point, Likert-type scale (1 = Spanish only, 2 = mostly Spanish, 3 = both English and Spanish, 4 = mostly English, 5 = English only). Higher scores indicated greater use of the English language.

Learning styles. The Learning Styles and Strategies survey (Felder \& Soloman, 2001) was designed to measure four types of learners: (a) active and reflective learners, (b) sensing and intuitive learners, (c) visual and verbal learners, and (d) sequential and global learners. The scale is composed of 44 items describing various ways in which people learn most effectively, with possible responses presented in a forced-choice, either-or manner. For instance, one of the items includes the following, "I understand something better after I? ' $a$ ' Try it out, or ' $b$ ' Think it through." Participants were given a score of 1 for each $a$ item selected and -1 for each $b$ item selected. Each subscale (i.e., the four types of learners) was composed of 11 questions. Subscale scores were computed by summing all 11 items. Total subscale scores close to 0 indicate that the learner is well balanced between the two complementary learning styles (i.e., active-reflective, sensing-intuitive, visual-verbal, and sequential-global). The farther from 0 the final sub- 
scale score, the greater the preference for one style (e.g., active learner) over another (e.g., reflective learner) for each of the four types.

\section{Data Analyses}

Quantitative data. All survey data were coded, entered into an SPSS file, and then checked for coding and entering errors. Data were analyzed using general descriptive statistics to establish means, modes, frequencies, and ranges. Comparative analyses, including correlational, $t$-test, and chi-square techniques were also used. Levene's test for equal variances did not yield statistically significant results between the two compared groups (i.e., former and current Career Ladder program participants), indicating that the assumption for homogeneity was not violated. A check on multivariate normality of the data showed the multivariate normality assumption was not violated.

Qualitative data. Thematic analysis (Aronson, 1994), a technique for analyzing textbased data, was used for analyzing the transcribed interview data. The analysis procedure begins by thoroughly reading all interviews (or protocols). Next, all interviews are re-read, and shared patterns of experience, or themes, evident across the interviews are extracted. In the present investigation, the majority of participants described challenges in maintaining active involvement in the Career Ladder program. Thus, challenging factors comprised one theme evident in the data. The next step, as noted by Aronson (1994), involves expounding on each theme by adding all information from the transcribed interviews that relates to already classified patterns. This step is significant because participants frequently refer to, or expound on, a particular topic or issue at numerous points throughout an interview. By thoroughly searching each interview for information relating to particular themes, one is able to capture all relevant data.

Next, similar patterns are combined and catalogued into subthemes. In this investigation, several subthemes emerged. Specifically, although the majority of participants described factors that challenged their active Career Ladder participation, the challenges differed considerably. Further analyses revealed several subthemes related to challenges that included family demands, personal health, and economic stability. Results of data analyses are described below.

\section{Results}

\section{Quantitative Data}

Depression. The mean score on the CES-D (depression) scale, for the entire group of 26, was 13.9 (scores ranged from 0-38), indicating that feelings of depression did not characterize the participants. However, closer examination of the data revealed that several $(n$ =9) participants scored above the clinical cutoff mark of 16.0; their average depressive score was 27.2 and ranged from 17 to 38. Thus, two groups were created: those with depressive scores above and below the clinical cutoff. Further analyses comparing the two 
groups revealed a statistically significant difference between them, with mean depressive scores of 27.2 and 6.8, respectively, $t(24)=11.1, p<.001$. Interestingly, among the six former Career Ladder participants, two received depressive symptom scores above the clinical cutoff point, indicating the possibility of mental health problems as contributing to program abandonment.

Social support. Scores of the PRQ85 revealed perceptions of strong social support among participants. Specifically, the average total support score was 147.4 (range = 103-175, $S D=19.2)$. Subscale means and standard deviations included the following: intimacy/assistance $(M=58.4, S D=10.0)$, social integration/affirmation $(M=52.6, S D$ $=6.6)$, and nurturance $(M=30.5, S D=3.30)$. Comparisons were made between those individuals with high (i.e., above $16 ; n=9)$ and low $(n=17)$ depressive scores, looking for differences in perceived social support. Statistically significant differences were found for the total support scores and for every support subscale, total support, $t(d f=$ $24)=.41, p<.001$, intimacy/assistance, $t(d f=24)=3.4, p<.001$, social integration/affirmation, $t(d f=24)=4.5, p<.001$, and nurturance, $t(d f=24)=2.6, p<.01$. (See Table 1 for mean comparison scores between the two groups for the total support scale and each of the support subscales.)

Language use. Participants were divided into two groups based on their average language use score, with those scoring more than 3 (indicating greater use of English) grouped separately from those scoring below 3 (indicating greater use of Spanish). No statistical differences were found between the two groups on total symptoms of depression, total support, or any of the three support subscales. However, in looking at the subgroup of nine with higher depressive scores specifically, analyses revealed a statistically significant difference between those reporting greater use of the English language compared to those with greater Spanish language use, $t(7)=-2.97, M=22.6, S D=4.7, p=.02$, Mann-Whitney $U=.50, N 1=5, N 2=4, p=.019$. These differences indicate that, among the most depressed group of nine, those reporting greater use of the English language were significantly more depressed than were their peers.

Acculturation. First and second generation immigrants $(n=20)$ reported that, on average, 8.6 acculturation items were personally applicable (range $=2-16$ ). The items most commonly reported as personally relevant, in order of frequency, included the following: being uncomfortable when people made jokes about or put down individuals of their ethnic background $(n=18)$, having frequent thoughts about culture and cultural background $(n=17)$, feeling negatively stereotyped by others based on ethnicity $(n=12)$, feeling like ethnicity was a limitation in finding a good job $(n=11)$, and having difficulty in loosening ties with home countries $(n=9)$. In addition to assessing those items that were personally relevant to participants, this acculturation instrument also allows for the assessment of the amount of stress associated with each issue. Importantly, it is possible that an item is personally relevant, but this does not necessarily mean that the issue causes or creates stress in an individual's life. Thus, analyses were conducted to examine the amount of stress created by the acculturation items. Participants indicated that the greatest amount of stress surrounded four issues: hearing jokes or put-downs about their 
Table 1. Means and Standard Deviations for Support Subscales: Comparing High and Low Depressive Symptom Groups.

\begin{tabular}{llrrr}
\hline Support Subscales & Groups & $n$ & $M$ & \multicolumn{1}{c}{$S D$} \\
\hline Intimacy/assistance & Depressed & 9 & 50.67 & 7.81 \\
& Not depressed & 17 & 62.41 & 8.70 \\
Social integration/affirmation & Depressed & 9 & 46.56 & 6.19 \\
& Not depressed & 17 & 55.82 & 4.25 \\
Nurture & Depressed & 9 & 28.44 & 1.23 \\
& Not depressed & 17 & 31.59 & 0.62 \\
Total support & Depressed & 9 & 130.78 & 14.86 \\
& Not depressed & 17 & 156.24 & 15.08 \\
\hline
\end{tabular}

own ethnic group, feeling that their ethnicity was a limitation in finding a good job, being treated as if negative ethnic-based stereotypes were true, and having a difficult time loosening ties with countries of origin.

Learning styles. As a group, participants were largely active, sensing, visual, and sequential learners, as opposed to being reflective, intuitive, verbal, or global learners. The total mean scores for each subscale were as follows: active-reflective $(M=2.2)$, sensingintuitive $(M=4.8)$, visual-verbal $(M=3.8)$, and sequential-global $(M=1.5)$. Most mean scores were close to 0 , indicating balance between the two complementary learning styles. Participants showed the greatest preference for the sensing and visual learning styles.

\section{Correlational Statistics}

Correlational analyses revealed several statistically significant relationships. Specifically, and as no surprise, total social support was negatively related to depression $(r=$ $-.63, p<.01)$. In other words, more support was related to fewer depressive symptoms. Given that the support scale was composed of 3 subscales, it was also not surprising that each of the three subscales was also significantly negatively related to depressive symptoms. Specifically, statistically significant negative relationships were observed between depression and intimacy/assistance $(r=-.57, p<.01)$, depression and social integration/ affirmation $(r=-.68, p<.01)$, and depression and nurturance $(r=-.43, p<.01)$.

Interestingly also is that, among first and second generation immigrants, scores on the total support scale were negatively related to feelings of acculturation stress $(r=-.45, p<$ .05). That is, the greater the amount of support perceived from network members, the less acculturation stress reported by participants. 
Data analyses revealed two differences between the active Career Ladder program participants and those who had dropped out of the program. First, active program participants reported having fewer children, on average, than those who had dropped out of the program (2.3 vs. 3.0, respectively). Although not statistically significant, the variation neared statistical significance $(t=-1.2, p=.08)$ and clearly warrants further attention in future investigations. Second, active program participants had lived in their respective communities, on average, nearly 6 years longer than had those who had dropped out $(t=$ $2.8, M=11.3$ years vs. 5.5 years, $p>.01$ ).

\section{Qualitative Data}

After completing the survey indices, each participant then engaged in an in-depth, open-ended interview. Spatial limitations preclude a complete discussion of all the data obtained through the interview format. However, participants' feelings regarding the strengths and the challenges of the distance education Career Ladder program are worthy of discussion.

Strengths. Participants described a number of program strengths. First, they overwhelming reported that the program had economic and financial strengths. Specifically, as part of program participation, participants' tuition was waived, and their books were received without charge. Each also received a laptop computer, for the duration of the program, to access their online courses. Without such financial assistance, the majority noted they would be unable to participate in the educational program. Another common strength noted by participants was the flexibility and ease of use of the program. They indicated that the work associated with registering for classes and scheduling was arranged for them. In addition, they did not even have to order their own books, as books were ordered for them and then delivered to their homes! Participants were deeply appreciative of the work completed by the Career Ladder coordinator on their behalf to make the program as user-friendly as possible. Numerous individuals also noted the social aspects of the program as a benefit or strength. That is, they had developed friendships with other Career Ladder participants that were both supportive and encouraging. Finally, many participants reported that the opportunity to earn their bachelor's degree and a teaching certificate was "a dream come true." They were excited and hopeful about their futures, and the program allowed for a lifelong goal, that of college graduation with the opportunity to teach in the public schools, to be realized.

Indirect benefits of program participation were also noted. Specifically, several participants reported that their children and families were proud of them and their accomplishments. Some remarked that their children placed a greater value on education because they saw their mothers doing homework and exerting a great deal of effort and energy toward obtaining their degrees. That is, the indirect, positive impact of the educational program on program participants' children was reported by numerous interviewees. 
Challenges. In addition to the program strengths and benefits, several challenges to program participation were also noted. The first and most commonly reported challenge to Career Ladder program participation was the amount of time required to maintain active involvement. Participants were required to work full-time (i.e., a minimum of 36 hours per week) as paraprofessionals in an elementary or middle school of their choice. In addition, to complete the program before grant funding ended (i.e., in 2007), participants were required to take four classes per semester and two classes during the summer months. Needless to say, the time demands created family hardships for many. Most of the participants were married $(n=21)$ and had children $(n=24)$, with children averaging 10.4 years of age, and 14 participants had children younger than 8 . Clearly, most participants were involved in intensive parenting, and many reported feeling overwhelmed and overworked. Some felt guilty over not spending as much time with their children as they felt they should or as they would like. And the majority felt exhausted trying to maintain their homes, their relationships with their spouses and children, their fulltime labor force participation, and their school work. Child care assistance was an urgent need noted by several.

Participants most able to adapt to the multiple demands on their time and energy reserves were those whose husbands or partners were supportive of their involvement in the Career Ladder program. Participants whose intimate partners actively encouraged their Career Ladder involvement and adjusted their own behavior to alleviate stress on their partners by assisting with household chores and child care appeared to be adjusting best.

Several $(n=4)$ noted that their partners were supportive of their participation in the Career Ladder program as long as their own lives (those of the partners) were not impacted. That is, as long as they did not have to adjust their own behavior or lifestyle. One participant, for instance, explained how her husband's attitude affected her ability to concentrate on classes. She explained, "I'm always watching the clock during class, because I have to be home on time-before he [her husband] gets home or else he will be upset." And another reported severe sleep deprivation because her husband refused to adjust his behavior to accommodate her need to study or do homework. She was responsible for all household chores and child care, including shopping and meal preparation. Homework, she stated, was typically done late at night after her children and husband were in bed.

Aside from familial obligations, another challenge associated with the program involved finances. Several participants reported experiencing financial difficulties because, by fulfilling the program requirement of working full-time as para-educators, they were forced to abandon higher paying employment (e.g., in the meat processing industry). However, they reported knowing that, once they had graduated with their teaching certificates, their financial status would improve dramatically. Thus, financial strain was a notable challenge associated with program participation, but they also recognized that the economic burden was temporary and that the long-term goal of earning their teaching degrees was worth the short-term difficulties. 


\section{Conclusion}

The purpose of this exploratory investigation was to assess personal, familial, and contextual factors that promote and/or challenge bilingual paraprofessional educators' ability to successfully complete an online, distance education (Career Ladder) program. In all, 26 individuals participated; 20 were active in the Career Ladder program, and 6 had dropped out.

Statistically speaking, the two groups looked remarkably similar. The largest differences between them included number of children, with active participants having fewer, and number of years they had lived in their respective communities (i.e., active participants averaged longer community residence). These data suggest that child care may be particularly necessary to maintain participants' successful involvement in this or other educational or intervention programs. The data also suggest that community integration maybeanimportantfactorinparticipants'abilitiestomaintainwork,family, and education. Social integration may be a proxy variable for knowledge about and access to sources of informal and formal support. Still, it is curious that no differences were found between the active and former Career Ladder program participants on indices of social support. Clearly, these findings deserve greater exploration.

Importantly, depressive scores were within the normal range for the majority of participants. Of concern however, is that a subsample of participants $(n=9)$ had elevated scores indicating symptoms of clinical depression. Interesting also is that two participants who had dropped out of the program were among the nine with the highest depressive symptom scores. These data suggest that depression may be a potential risk factor for program failure. Furthermore, mental health care services are notoriously lacking in rural areas (Doyle, 1998). The data strongly suggest that assessment of and attention to mental health care issues may be warranted among rural populations.

Social support is strongly associated with positive mental health; depressive symptoms were lowest among those reporting the greatest amount of social support. However, cause and effect relationships cannot be assumed; social support does not necessarily cause or lead to positive mental health. It is also likely that individuals with positive mental health are better equipped to develop and maintain supportive social relationships. The data certainly suggest, however, that the two are related. Thus, strengthening the support networks of participants, particularly those with greater depressive symptoms, may be an effective strategy for improving mental health.

Relationships with husbands or intimate partners were noted as particularly critical to participants' mental and physical health, as revealed through the qualitative interviews. Participants with partners who assisted in household and child care tasks reported feeling less concerned about their ability to complete the entire 5-year Career Ladder program and, further, reported greater ease in maneuvering the multiple demands on their time and energy. When asked how to improve the program, particularly in relation to its impact on familial relationships, several noted that family members should be included in the program. Spouses and children could be included through intermittent social gatherings or home projects related to educational goals to increase their understanding of the program. By extension, such involvement may indirectly foster greater support for Career Ladder participants by family members. 
Previous investigations examining depression and social support among Hispanic women provide insight into the present findings. In an examination of marital strain, coping, and depression among 550 urban Mexican American women, Vega, Kolody, and Valle (1988) found direct effects between marital strain and coping and depressive symptoms. Similarly, Aranda, Castaneda, Lee, and Sobel (2001) examined gender differences in stress, social support, and coping in relation to depressive symptoms among Mexican Americans. Interestingly, male psychological well-being was affected by social support from outside sources. Among the women, support from the marital relationship was related to psychological well-being. Women with low levels of spousal support reported greater depressive symptoms. Unfortunately, few investigators have examined marital and family strain among rural populations, even fewer among rural Hispanic populations. Studies of mental health among rural, immigrant populations are particularly limited; future studies in this area would prove particularly valuable for program development and service provision.

Finally, understanding learning styles is important for gearing educational material toward Career Ladder program participants' strengths. Participants' preferred learning styles tended to be active, sensing, visual, and sequential, with the strongest preferences toward sensing and visual styles. Sensing learners tend to like facts (vs. discovering possibilities and relationships); they like to solve problems by well-established methods and dislike complications and surprises. They do not like being tested on material that has not been explicitly covered in class, and visual learners remember best what they see (e.g., pictures, diagrams, flow charts, demonstrations). However, in most college classes very little visual information is presented; most information is presented in the form of lectures. Although such strategies may prove quite effective for verbal learners, they present difficulties and challenges for visual learners. According to Felder and Soloman (2001) several strategies can be used to strengthen learning, regardless of students' preferred styles. Sensors remember and understand information best if they can see how it connects to the real world; abstract, theoretical material should be connected to concrete examples. The applicability of abstract material should be demonstrated to capitalize on the sensors' strengths. If instructors do not provide connections, it is recommended that sensors work with friends or peers to brainstorm the applicability of course material. Felder and Soloman (2001) further suggest that visual learners explore strategies (e.g., creating diagrams and charts and color coding notes) for turning text-based information into visually relevant information. Better understanding of one's own learning style could prove beneficial for all students, not only rural immigrants enrolled in distance education courses. However, because of the lack of personal, physical contact between online learners and their instructors, coupled with limited resources for assisting distance students (e.g., tutors) available in rural communities, knowing one's preferred learning style and developing strategies for adapting to various teaching methods could prove particularly beneficial for rural, distance students.

The ability of rural schools to meet the growing demand of bilingual, ESL, and LEP students has increased dramatically during the past decade. This need will continue to grow (WEBARCHIVES, 2000). The Career Ladder program offers a phenomenal opportunity to meet this need by allowing rural, bilingual, paraprofessional educators to earn their college degrees and teaching certificates online. The present investigation provides valuable 
data regarding factors relevant for understanding the unique needs of rural, paraprofessional educators. Increasingly, many services to needy and marginalized groups are provided through private rather than public agencies and typically through private or religious donations (LeDoux \& Stephens, 1992). Rural communities, like urban and inner-city geographies, are challenged to take a greater role in providing for their residents. It is paramount that the growing diversity of rural communities shape the diversity of services offered; resource utilization will be worthless unless designed to meet the unique needs of clientele.

\section{Note}

1. According to the U.S. Census Bureau (2000), Hispanic refers to those classifying themselves as Mexican, Mexican American, Chicano, Puerto Rican, or Cuban or those whose origins are from Spain or Spanish-speaking countries of Central or South America.

\section{References}

Allen, J. (1993). Development in a community under stress. Community Development Journal, 28(2), 154-166.

Aranda, M. P., Castaneda, I., Lee, P., \& Sobel, E. (2001). Stress, social support, and coping as predictors of depressive symptoms: Gender differences among Mexican Americans. Social Work Research, 25, 37-48.

Aronson, J. (1994). A pragmatic view of thematic analysis. The Qualitative Report, 2(1), 1-3.

Bjerklie, S. (1995). On the horns of a dilemma: The U.S. meat and poultry industry. In D. D. Stull, M. J. Broadway, \& D. Griffith (Eds.), Any way you cut it: Meat processing and small-town America (pp. 41-60). Lawrence: University Press of Kansas.

Broadway, M. J. (2000). Planning for change in small towns or trying to avoid the slaughterhouse blues. Journal of Rural Studies, 16, 37-46.

Broadway, M. J., Stull, D. D., \& Podraza, B. (1994, July). What happens when the meat packers come to town? Nebraska Municipal Review, pp. 8-12.

Dalla, R. L., Cramer, S., \& Stanek, K. (2002). Long-term residents' and immigrants' perceptions of economic strain and community issues: Survey results from three rural, meat-packing $\mathrm{Ne}-$ braska communities. Rural America, 17(1), 20-25.

Dalla, R. L., Villarruel, F., Cramer, S., \& Gonzalez-Kruger, G. (2004). Rural community change, strengths, and challenges: Long-term residents describe impacts of rapid immigration. Great Plains Research, 14(2), 231-252.

Doyle, R. (1998). Where the doctors aren't. Scientific America, 279(4), 31.

English Language Acquisition, Language Enhancement, and Academic Achievement Act of 2002, Pub. L. No. 107-110, § 3102, 115 Stat. 1690 (2002).

Federation for American Immigration Reform. (2001). Retrieved September 12, 2002, from http:// www.fairus.org/html/o42nbimpact.html

Felder, R. M., \& Soloman, B. A. (2001). Index of Learning Styles Questionnaire, North Carolina State University. Retrieved October 16, 2003, from http://www.ncsu.edu/unity/lockers/users/f/felder/public/ILSdir/ISL-a.html

Fitchen, J. (1991). Endangered spaces, enduring places: Change, identity and survival in rural America. Boulder, CO: Westview. 
Gouveia, L., \& Stull, D. D. (1995). Dances with cows: Beefpacking's impact on Garden City, Kansas, and Lexington, Nebraska. In D. D. Stull, M. J. Broadway, \& D. Griffith (Eds.), Any way you cut it: Meat processing and small-town America (pp. 85-107). Lawrence: University Press of Kansas.

Hovey, J. D. (2000). Acculturative stress, depression, and suicidal ideation in Mexican immigrants. Cultural Diversity and Ethnic Minority Psychology, 6, 134-151.

LeDoux, C., \& Stephens, K. S. (1992). Refugee and immigrant social service delivery: Critical management issues. In A. S. Ryan (Ed.), Social work with immigrants and refugees (pp. 31-45). New York: Haworth.

Mena, F. J., Padilla, A. M., \& Maldonado, M. (1987). Acculturative stress and specific coping strategies among immigrant and later generation college students. Hispanic Journal of Behavioral Sciences, 9, 207-205.

Nebraska Department of Education. (2000). Retrieved October 3, 2003, from http://ess.nde.state. ne.us/

Prochaska-Cue, K., \& Ziebarth, A. (1997). Growth and locational impacts for housing in small communities. Rural Sociologist, 62(1), 111-125.

Radloff, L. (1977). The CES-D scale: A self report depression scale for research in the general population. Applied Psychological Measurement, 1, 385-401.

Roberts, R. (1980). Reliability of the CES-D in different ethnic contexts. Psychiatry Research, 2, 125.

Stull, D. D., Broadway, M. J., \& Erickson, K. (1992). The price of a good steak: Beef packing and its consequences for Garden City, Kansas. In L. Lamphere (Ed.), Structuring diversity (pp. 35-64). Chicago: University of Chicago Press.

U.S. Census Bureau. (2000). FedStats. Retrieved October 3, 2003, from http://www.fedstats.gov/qf/ meta/long_68188.htm

Vega, W. A., Kolody, B., \& Valle, R. (1988). Marital strain, coping, and depression among MexicanAmerican women. Journal of Marriage and the Family, 50, 391-403.

WEBARCHIVES. (2000). U.S. immigration. Retrieved December 11, 2003, from http://www.americanpatrol.org/_WEBARCHIVES2000/web083000.html

Weinert, C. (1987). A social support measure: PRQ85. Nursing Research, 36, 273-277.

Whitener, L. A. (2001). Housing poverty in rural areas greater for racial and ethnic minorities. Rural America, 15(2), 2-7.

Rochelle L. Dalla, Ph.D., is an associate professor in the Department of Family and Consumer Sciences at the University of Nebraska-Lincoln. Her research interests include immigrant Latino family adaptation, particularly among those residing in rural communities of the Midwest.

William E. Lopez, Ed.D., is a senior lecturer in the Department of Teaching, Learning, and Teacher Education at the University of Nebraska-Lincoln. His primary interests include language acquisition and research into effective teaching practices in math, science, and social studies for limited English proficient students.

Vicky O. Jones is the extended education coordinator at the University of Nebraska-Lincoln Northeast Research and Extension Center. Her research interests include the retention of highly nontraditional undergraduate distance education students and development of cultural capital in rural communities of the Midwest.

Yan Xia, Ph.D., is an assistant professor in the Department of Family and Consumer Sciences at the University of Nebraska-Lincoln. Her research interests include the behavioral and mental health of youth and acculturation processes of new immigrant families. 